\title{
Multi resonance patch antenna with multiple slits
}

\author{
Merjem Begovic ${ }^{1}$, Sehabeddin Taha İmeci $^{1^{*}}$ \\ ${ }^{1,2}$ Department of Electrical and Electronics Engineering, International University of Sarajevo, Sarajevo, Bosnia
}

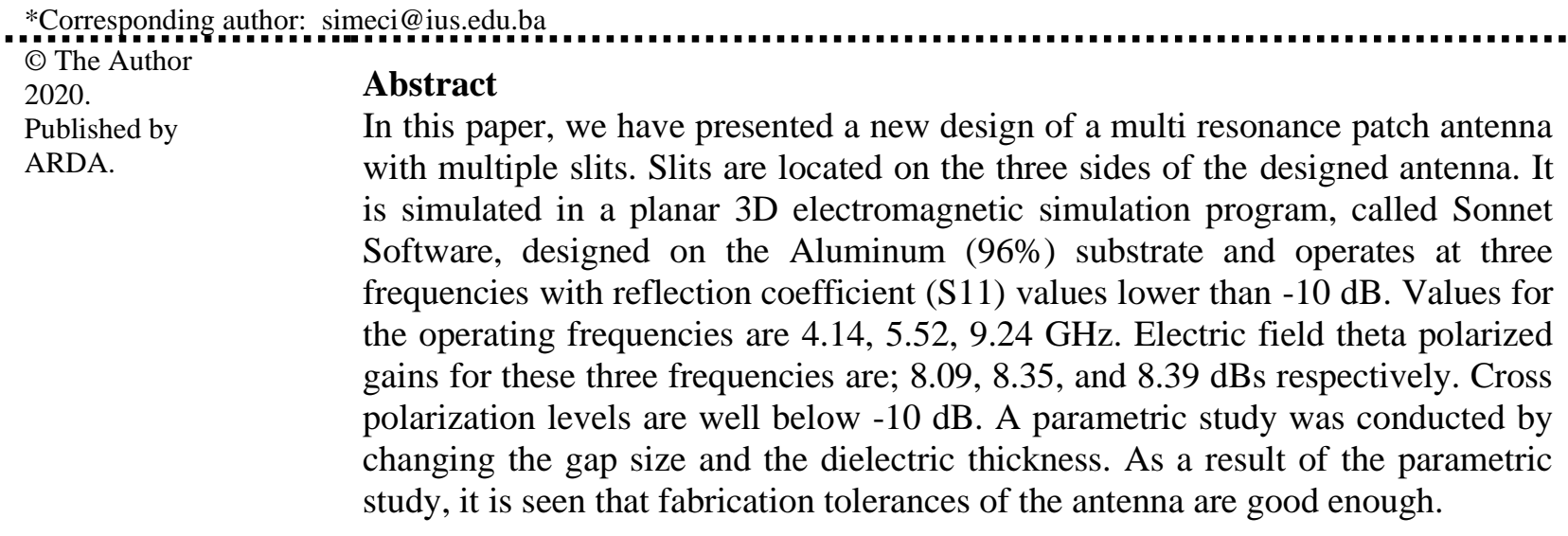

Keywords: Slits, Gain, Microstrip, Antenna, Polarization

\section{Introduction}

Rapid growth in mobile communication systems requires use of low profile, light weight, simple design and low-cost antennas in order to get efficient results. Those systems that transmit antennas in their free space can tie-up mobility, accessibility and can have sufficient range without amplification. Microstrip antenna was not developed until 1970 when the revolution in electronic circuit miniaturization started [1]. Choosing the proper antenna is based upon the requirements of the application regarding frequency band, gain, cost, coverage, weight, etc.[2]. Microstrip patch antennas are being used for a long time due to satisfying those requirements. But, still, they have disadvantages such as narrow frequency band and low gain, which could be modified and increased with many proposed methods in the literature [3]. Low gain microstrip antenna is consisted of conducting patch and ground separated by dielectric substrate.

There are many methods of designing the antenna regarding the requirements of the application. Many studies showed the wideband microstrip patch antennas for wireless communication [4] [5]. The authors of [6] used the concept of complementary antennas where the planar antenna is presented with U-shaped metal reflector in order to achieve unidirectional propagation. The antenna was low profile, high frequency band and high gain over the operational frequency range. In [7] wideband slot antenna was designed proposing the multiple metal back reflector. Interest in multi-band antenna is increasing to reduce the number of antennas used while combining multiple applications. In order to increase bandwidth multiple techniques are used, such as: using Frequency Selective Surface, using thicker profile for folded shorted patch antennas, use of slots, use of thicker substrate, E-shaped patch antenna, etc. [2].

Constantly trying to increase bandwidth, the researchers came up to an idea of using multiple slits which enhanced bandwidth to the level that they could cover multiple bands in the same time, which made usage much cheaper. There are reporting that those antennas have much less radiation loss [8]. Researches also reported that combining a various slot types in single layer single patch antenna is the best way to increase bandwidth and get the moest efficient antenna propagation [9].

This work is licensed under a Creative Commons Attribution License (https://creativecommons.org/licenses/by/4.0/ ) that allows others to share and adapt the material for any purpose (even commercially), in any medium with an acknowledgement of the work's authorship and initial publication in this journal. 
The most popular patch shape is rectangular which can be easily analyzed and modified in order to get desired results, but here we will propose different design which has been simulated and reflects the design of multi slot patch antenna which is going to ensure improving the multiband frequency operating range.

\section{Design methodology}

Multi slit patch antenna designs have been proposed in many literatures, and most used designs were offering E-, U- and V-shaped designs of mentioned antennas [10] [11] [12]. Through researching it is proved that Eshaped antenna has much better response and increased bandwidth due to current flow in two different paths generating two resonant frequencies which are coupling each other and improving the bandwidth compared to rectangular patch antennas [13].

In our design we have increased the number of slits in three sides and is simulated in Simulink. The size of the antenna is $75 \times 84 \mathrm{~mm}$. The antenna is designed on an Aluminum (96\%) dielectric substrate whose thickness and permittivity are $1.6 \mathrm{~mm}$ and 3.2 , respectively.

The design of the top view of the antenna and current dissipation through it can be seen in Fig. 1. The current dissipation is taken for 9.94 frequency, where we can see its best performance.

\section{Simulation results and parametric study}

In this section, simulation results of the antenna and related parametric study of the gap size and the dielectric thickness is introduced.

The general results were simulated at frequencies between $4 \mathrm{GHz}$ and $10 \mathrm{GHz}$, with input match shown in Fig. 2. In order to get better results, we set the cell size to 1, and since the box size is much bigger than cell's size the simulation took a bit more time.

Fig. 3, 4 and 5 has the electric field theta polarized gain values of the antenna. Gain patterns have three directive angles because of the multiple slits located in three sides of the patch antenna. Note that, cross polarized (phi) values are below $-10 \mathrm{~dB}$ in all three graphs.

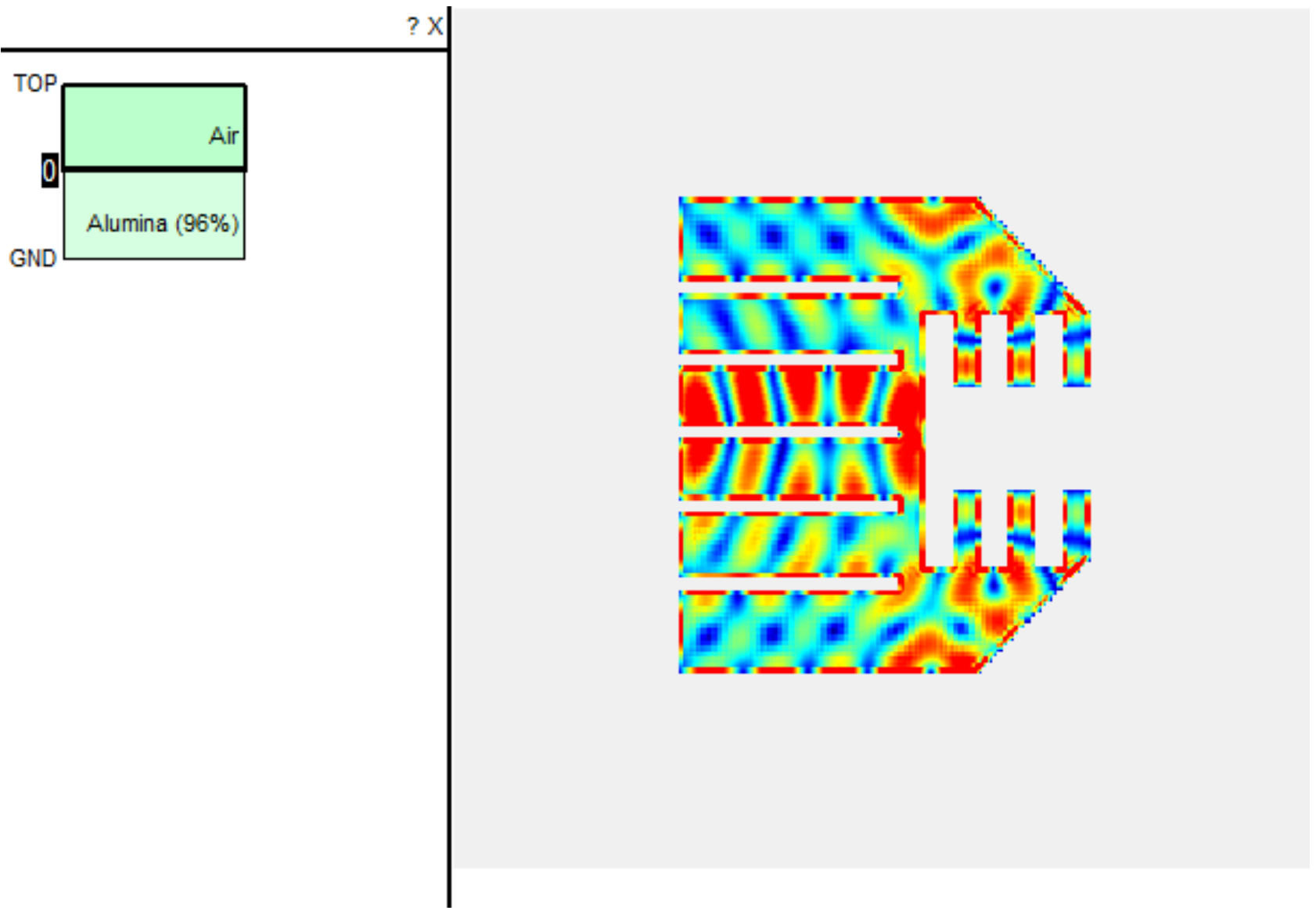

Figure 1. Top view of the antenna with current dissipation shown 
The multi resonance effect was achieved by playing with some of the parameters and changing them accordingly. In the Fig. 2, S11 is plotted against frequency, so there we can see the multi resonance effect.

In the best case we could get three points where the frequencies are intersected with the values of S11 which are lower than $-10 \mathrm{~dB}$.

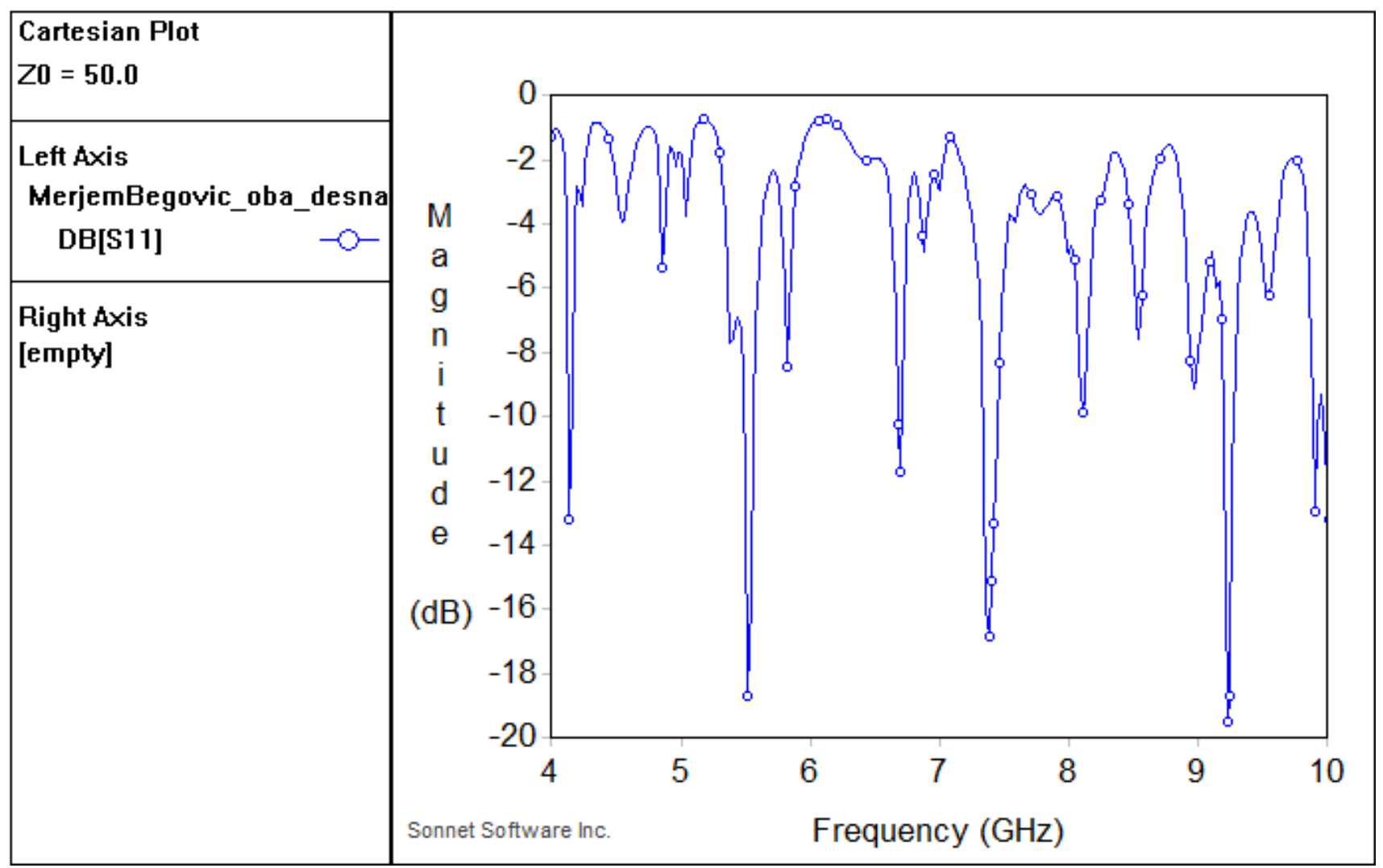

Figure 2. S11 graph

In the first table we have shown the results with the values that have been simulated for the showed S11 graph. Results show the value of the gain at the particular frequencies.

Table 1. Values of the gain

\begin{tabular}{cccc}
\hline $\begin{array}{c}\text { Frequency } \\
(\mathbf{G H z})\end{array}$ & $\begin{array}{c}\text { Gain } \\
(\mathbf{d B})\end{array}$ & $\begin{array}{c}\text { Theta } \\
(\text { degrees })\end{array}$ & $\begin{array}{c}\text { Ephi } \\
(\mathbf{d B})\end{array}$ \\
\hline 4.14 & 8.096 & 0 & -7.97 \\
5.52 & 8.358 & -5 & -13.81 \\
9.24 & 8.396 & 55 & -11.34 \\
\hline
\end{tabular}

In the figures below, the plot of the gain and theta are shown in correspondence with their frequencies. The values are shown in Table 1. 


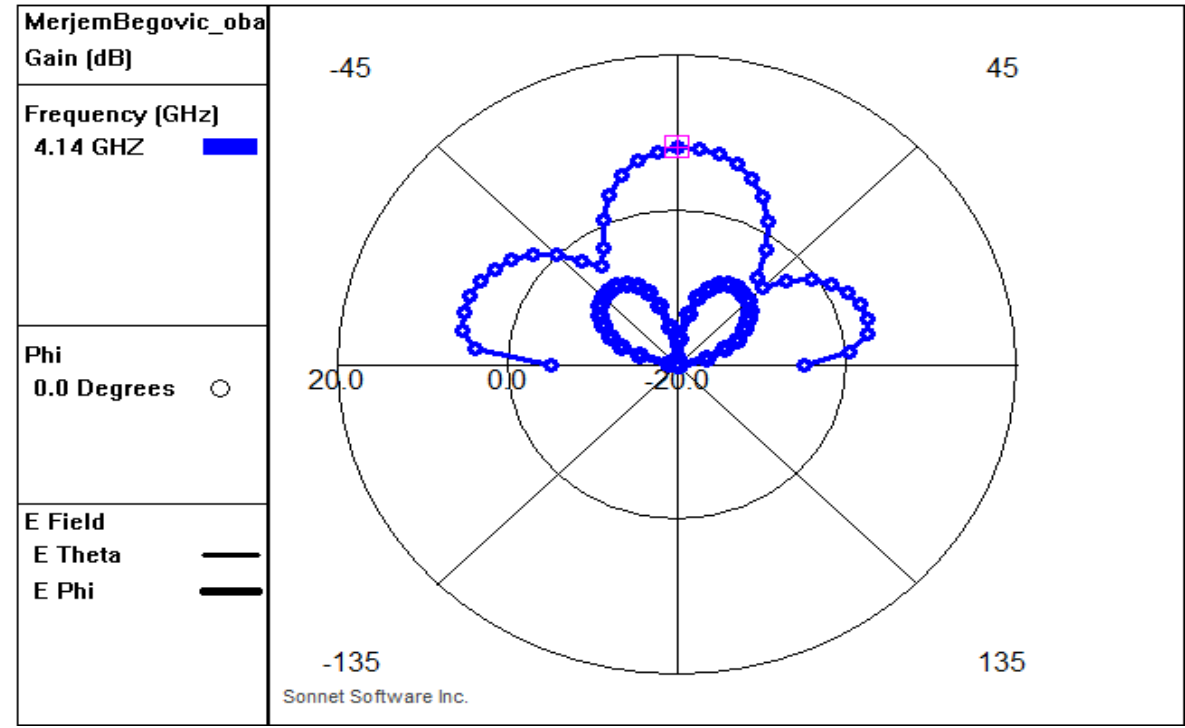

Figure 3. Gain value at $4.14 \mathrm{GHz}$

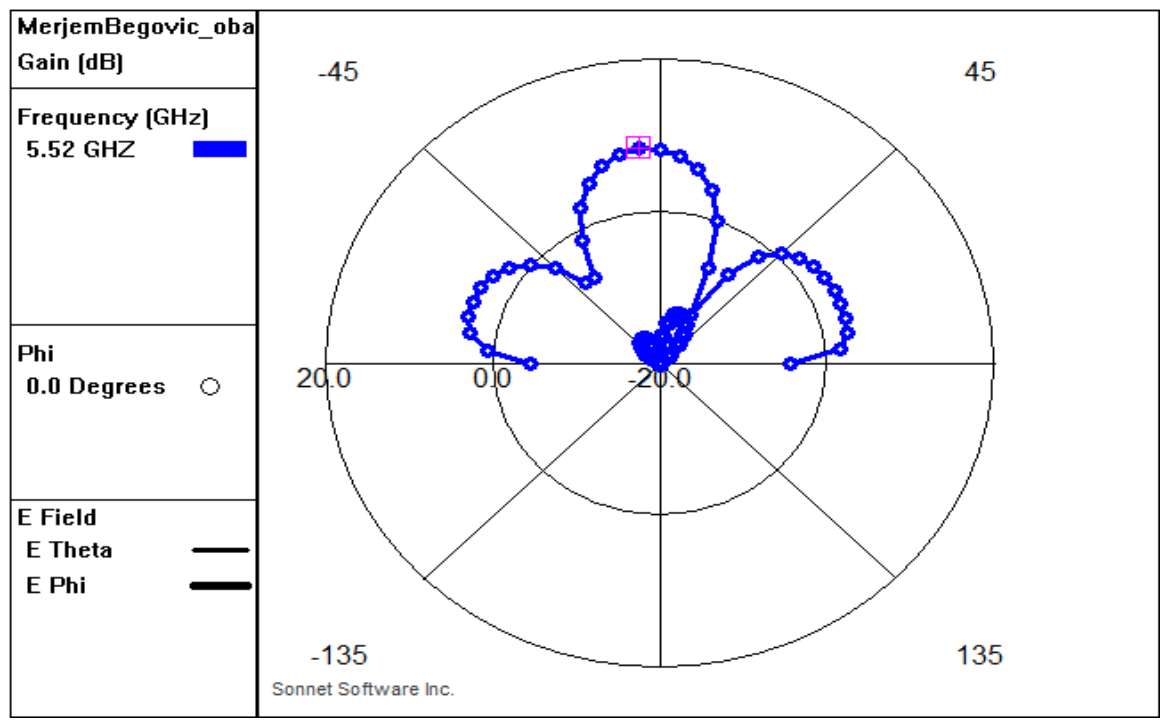

Figure 4. Gain value at $5.52 \mathrm{GHz}$

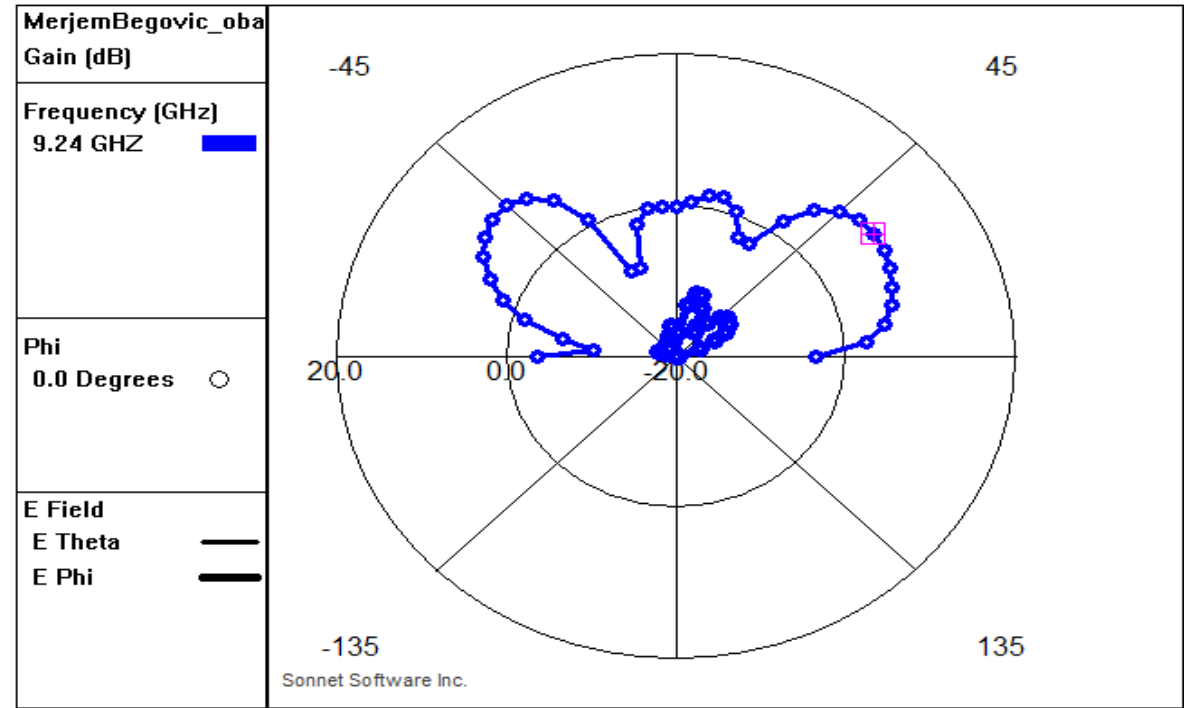

Figure 5. Gain value at $9.24 \mathrm{GHz}$ 
Changing the parameters, the number of resonance frequencies variated. The gain values decreased and values of the frequencies changed.

Firstly, we changed the size of the gap on the right handisede of the antenna, and got the results below:

Table 2. Gap Size $=16$

\begin{tabular}{c|c|c} 
Frequency & Gain & Theta \\
\hline 5.5 & 8.96 & -5
\end{tabular}

Table 3. Gap Size $=8$

\begin{tabular}{c|c|c}
\hline Frequency & Gain & Theta \\
\hline 5.44 & 10.65 & 0 \\
\hline
\end{tabular}

Table 4. Gap Size $=2$

\begin{tabular}{c|c|c}
\hline Frequency & Gain & Theta \\
\hline 5.5 & 8.87 & 0 \\
\hline 9.16 & 9.45 & 50 \\
\hline 9.32 & 7.38 & 60 \\
\hline
\end{tabular}

From the results that we showed in the tables above, we can see that increasing the gap size decreases the number of resonance frequencies but increases the values of the gain.

Next parameter that we were changing was thickness of the dielectric and got the results shown in tables below:

Table 5. Thickness $=1.4$

\begin{tabular}{c|c|c}
\hline Frequency & Gain & Theta \\
\hline 4.14 & 8.87 & -65 \\
\hline 5.54 & 9.45 & -5 \\
\hline 9.24 & 7.38 & 55 \\
\hline
\end{tabular}

Table 6. Thickness $=1.8$

\begin{tabular}{c|c|c}
\hline Frequency & Gain & Theta \\
\hline 5.5 & 8.312 & -5 \\
\hline 9.2 & 7.69 & 55 \\
\hline
\end{tabular}

Table 7. Thickness $=1$

\begin{tabular}{c|c|c}
\hline Frequency & Gain & Theta \\
\hline 5.58 & 8.545 & 0 \\
\hline 9.26 & 9.46 & -45 \\
\hline
\end{tabular}

Changes in the thickness affected the gain values and number of resonance frequencies, but this case is different from the changing the gap size. Here we cannot say exactly how the changes in thickness affect frequencies and gain value.

We also changed the permittivity and got results showed in table below: 
Table 8 . Erel $=2.8$

\begin{tabular}{c|c|c}
\hline Frequency & Gain & Theta \\
\hline 4.42 & 7.58 & 5 \\
\hline 5.88 & 8.26 & -5 \\
\hline 9.82 & 8.605 & 50 \\
\hline
\end{tabular}

Table 9. Erel $=3.8$

\begin{tabular}{c|c|c}
\hline Frequency & Gain & Theta \\
\hline 5.1 & 8.70 & -5 \\
\hline 8.5 & 6.819 & -50 \\
\hline
\end{tabular}

Table 10. Erel $=4.4$

\begin{tabular}{c|c|c}
\hline Frequency & Gain & Theta \\
\hline 4.74 & 8.372 & -5 \\
\hline 7.92 & 5.32 & 70 \\
\hline
\end{tabular}

As it was the case with changes in the thickness, we cannot say how frequency and gain values will change during the change of the permittivity.

\section{Conclusion}

In this paper, multi resonance patch antenna with multiple slits is designed and simulated and their operating frequencies are 4.41, 5.52. 9.24 GHz. The proposed antennas design consists of rectangular patch structure with multiple slits as a novel shape of the patch. The proposed antennas provide useful frequencies and good radiation characteristics. The simulation results of the gain for the proposed antenna are 8.096, 8.358 and $8.396 \mathrm{~dB}$ at resonating frequencies $4.41,5.52 .9 .24 \mathrm{GHz}$, respectively. Next work is fabrication and measurement of the antenna in unechoing chamber.

\section{References}

[1] M. K. Bhanarkar, V. V. Navarkhele and A. A. Shaikh, "Low Gain Microstrip Patch Antenna for Wireless Applications," in NCMTA-2013, At Azad college, Aurangabad, 2013.

[2] R. KARLI and H. AMMOR, "A SIMPLE AND ORIGINAL DESIGN OF MULTI-BAND," International Journal of Microwaves Applications, p. 4, 2013.

[3] C.-L. Mak, H. W. Luk and Kwai-Man, "High-Gain and Wide-Band Single-Layer PatchAntenna for Wireless Communications," IEEE TRANSACTIONS ON VEHICULAR TECHNOLOGY, p. 8, 2005.

[4] P. Ranjan and S. Mishra, "Design of Circularly Polarized Rectangular Patch Antenna with single cut," in Conference on Advances in Communication and Control Systems, 2013.

[5] N. J. Shimu and A. Ahmed, "Design and performance analysis of rectangular microstrip patch antenna at $2.45 \mathrm{GHz}, "$ in 5th International Conference on Informatics, Electronics and Vision (ICIEV), Dhaka, 2016.

[6] M. Li and K. M. Luk, "A low-profile wideband planar antenna," IEEE Transactions on Antennas and Propagation, vol. 61, p. pp. 4411-4418, 2013.

[7] X. Gao and Y. Q. \&. Y. C. Jiao, "Design of multiplate back-reflector for a wideband slot antenna," IEEE Antennas and Wireless Propagation Letters.

[8] M. A. Layegh, G. Changiz and N. Javad, "The Optimization Design of a Novel Slotted Microstrip Patch Antenna with Multi-Bands Using Adaptive Network-Based Fuzzy Inference System," 
Technologies, vol. 5, no. 75, 2017.

[9] P. Chowdary, A. Prasad and P. Rao, "Multi Resonant Structures on Microstrip Patch for Broadband," in 3rd International Conference on Frontiers of Intelligent Computing: Theory and Applications (FICTA), 2015.

[10] F. Yang, X. Zhang, X. Ye and Y. Rahmat-Samii, "Wide-band E-shaped patch antennas for wireless communications," IEEE Trans. AntennasPropag., vol. 49, pp. 1094-1100, 2001.

[11] G. Rafi and L. Shafai, "Broadband microstrip patch antenna with V-slot," IEE Proc., Microw. Antennas Propag., vol. 151, pp. 435-440, 2004.

[12] A. Deshmukh and G. Kumar, "Compact broadband E- shaped microstrip antenna," Electron Lett, vol. 151, pp. 989-990, 2005.

[13] B. K. Jagadeesh, L. Reddyca and K. S. Ramakrishnab, "A symmetric multi slot patch antenna with improved bandwidth and isolation for wireless MIMO systems," Procedia Engineering, vol. 30, pp. 978-982, 2012. 